\title{
Research Paper: Translation, Validity, and Reliability of the Persian Version of the Fisher Auditory Problems Checklist
}

\author{
Sanaz Shakiba1 $^{1}$, Nematollah Rouhbakhsh ${ }^{1 *}$ (D), Qasem Mohammadkhani', Farzaneh Zamiri Abdollahi', Elham Faqih Zadeh
}

1. Department of Audiology, School of Rehabilitation, Tehran University of Medical Sciences, Tehran, Iran.

2. Department of Statistics, Faculty of Mathematical Sciences, Shahid Beheshti University, Tehran, Iran.

\begin{tabular}{|c|c|}
\hline $\begin{array}{l}\text { Use your device to scan } \\
\text { and read the article online }\end{array}$ & Citation Shakiba S, Rouhbakhsh N, Mohammadkhani Q, Zamiri Abdollahi F, Faqih Zadeh E. Translation, Validity, and Reli- \\
\hline 口ifing & $\begin{array}{l}\text { ability of the Persian Version of the Fisher Auditory Problems Checklist. Journal of Modern Rehabilitation. 2018; 12(3):169-180. } \\
\text { http://dx.doi.org/10.32598/JMR.V12.N3.169 }\end{array}$ \\
\hline 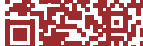 & del'http://dx.doi.org/10.32598/JMR.V12.N3.169 \\
\hline
\end{tabular}

\section{(i) (5)}

Article info:

Received: 30 Nov 2017

Accepted: 28 Mar 2018

Available Online: 01 Jul 2018

\section{Keywords:}

Central Auditory Processing Disorder, Dichotic Digit Test, Fisher Auditory Problem Checklist, Word in Noise Test

\section{A B S T RACT}

Introduction: In 1996, American Speech-Language-Hearing Association (ASHA) introduced the need for an appropriate screening tool for Auditory Processing Disorder (APD). Questionnaires are one of the tools to screen APD, of which the most frequent one is the Fisher auditory checklist. The current study aimed at translating and determining the validity and reliability of the Persian version of the Fisher checklist.

Materials and Methods: The current checklist developing study was conducted on 25 children ( 12 males and 13 females) aged 8 to 12 years (Mean $\pm \mathrm{SD}=9.4 \pm 1.3$ ) with $\mathrm{APD}$ as the case group, and 25 normal children ( 14 males and 11 females) aged 8 to 12 years (Mean $\pm \mathrm{SD}=9.5 \pm 1.4$ ) as the control group. The translation process was performed according to international guidelines. Indicators of formal validity, test-retest reliability, and internal consistency of the questionnaire were assessed. Then, to check the effectiveness of the questionnaire to identify children with APD and normal children, the checklist was examined along with paired Dichotic Digit Test (DDT) and Word in Noise Tests (WNT).

Results: The average score of the Persian version of the Fisher checklist was $46.6 \pm 16.7$ in the case group and $94.7 \pm 12.5$ in the control group. The Cronbach's alpha for the Fisher checklist at the test stage was 0.827 and in the retest stage, the Cronbach's alpha in the patient group was 0.845 and in the control group was 0.709 . The Intraclass Correlation Coefficient (ICC) values in the case and control groups were 0.708 and 0.744 , respectively.

Conclusion: According to the results of DDT and WNT, the Persian version of the Fisher checklist had face validity (face value: 3.4 ) and intrinsic reliability of APD detection.

\section{Introduction}

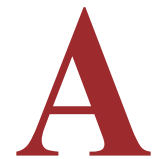

udiologists usually evaluate the peripheral auditory system of clients referring to clinics, but it should be noted that hear- ing impairment can be either due to problems with the Central Auditory Processing (CAP) system or the peripheral system. Therefore, it seems reasonable to take into account both the peripheral and the central auditory systems in auditory evaluations; therefore, with a com-

* Corresponding Author:

Nematollah Rouhbakhsh, PhD

Address: Department of Audiology, School of Rehabilitation, Tehran University of Medical Sciences, Tehran, Iran.

Tel: +98 (21) 77530636

E-mail: rohbakhn@tums.ac.ir 
prehensive view, it is possible to identify persons with communication disorders, language and learning problems, and as far as possible, the negative consequences of psychological, educational, personal, and social involvements of these disorders are reduced.

Auditory processing involves all processes that determine the position of the sound source in space and the type (nature and content) of the stimulus, and separates the stimulus from the background noise and provides signal processing and ultimately its interpretation $[1,2]$. In general, the CAP behaviors are responsible for sound lateralization and localization, dichotic hearing, auditory discrimination, auditory temporal processing, and auditory performance with competing or degraded acoustic signals [2-4]. In Auditory Processing Disorder (APD), one or more of CAP behaviors are impaired. To identify and diagnose APD, generally, two evaluation approaches are used: central tests including psychoacoustic and electrophysiologic, as well as questionnaires or checklists, which are mainly screening tools [5].

There are a large number of questionnaires that can be used as clinical and research tools to work with students suspected of having APD, and are, in many respects, essential for clinical trials and evaluations. In a study on 195 educational audiologists for the screening and diagnosis of APD, it was found that $75 \%$ of them used questionnaires. These questionnaires included the Buffalo model questionnaire [6], children auditory performance scale [7], children home inventory for listening difficulties [8], listening inventories for education [9], scale of auditory behaviors [10], auditory processing domains questionnaire [11], screening instrument for targeting educational risk [12], and the Fisher auditory problem checklist (Appendix) [13].

According to the study, audiologists used $63 \%$ of the Fisher checklists. In the next ranking, CHAPS questionnaire $(51 \%)$ and SIFTER questionnaire (39\%) were used [1]. These statistics point to the importance of using the Fisher checklists and the preparation of the Persian version of this useful checklist. Of these three common questionnaires, a Persian version of the SIFTER questionnaire was prepared by Fattahi et al. in Tehran University of Medical Sciences (TUMS). At the time of conducting the present study, a Persian version of the CHAPS questionnaire was prepared by Mahdavi et al. at Shahid Beheshti University of Medical Sciences.

Strange et al. (2011) examined the usefulness of the Fisher checklist to screen children with APD. They investigated the relationship between the Fisher checklist and the Buffalo tests in 40 children aged 6-13 years from 2003 to 2008. They found that the children that scored less than $72 \%$ on the Fisher checklist were also often demonstrated abnormal scores in the Staggered Spondee Word (SSW) test [3]. According to the high sensitivity reported for the Buffalo test battery in detecting APD, as well as the correlation between the Fisher results and this test battery, the Fisher seems to be a useful screening tool for APD. Consequently, due to the reliability and importance of the Fisher checklist in the screening of APD and lack of its Persian version, the current study aimed at translating and evaluating the validity and reliability of the Persian version of the Fisher checklist

\section{Materials and Methods}

The development of the Persian version of the Fisher Auditory Problems Checklist was based upon the international Beaten et al. guideline to develop a checklist. In the translation section, there were two translators in forward translation (English to Persian translation) and two translators in backward translation (Persian to English translation). For the purpose of examining the quality of the translation, hence, to maintain the translation quality, a committee of experts was formed. After consultation with the expert committee, the final Persian version of the checklist was prepared and re-translated into English by two leading English audiologists in Iran and one audiologist based in Canada.

To confirm the quality and authenticity of the translation, the final version of the translation was then sent to a native English audiologist that was an expert in the Fisher checklist. In order to study the face validity of the Persian version of the Fisher checklist, 10 expert audiologists were asked to evaluate how the words, and hence the sentences employed in the forward translation looked like and whether they measured what they were supposed. The experts used a four-point Likert scale (from 1 as "very weak" to 4 as "good") to evaluate the relationship of the checklist questions with the measured variable.

In order to examine the clarity and meaning of the questions, 25 parents of APD children (12 males and 13 females with the mean age of $9.4 \pm 1.3$ years) and 25 parents of normal children (14 males and 11 females with the mean age of $9.5 \pm 1.4$ years) were also recruited. The parents were asked to give their opinion on the comprehensibility and the absence of any ambiguity or unclarity regarding each of the individual questions in the form of a four-point Likert scale [14, 15]. 
To assess reliability, the Fisher checklist was completed and rated by the same parents in a period of two weeks. Children with APD and normal children aged 8 and 12 years, eligible for participation in the study, were recruited based on inclusion criteria via simple random sampling technique. Both the control and patient groups had peripheral normal hearing and were right-handed according to the Edinburgh questionnaire.

Children with APD recruited from Newsha and Ordibehesht rehabilitation centers, working with children with APD, and the normal children were recruited from children's cultural center and summer activities centers. All participates had no history of hearing involvements including outer, middle, and inner ears. Hearing sensitivity in all participants was $\leq 20 \mathrm{~dB} H \mathrm{HL}$ at octave frequencies from $125-8000 \mathrm{~Hz}$ with symmetric thresholds bilaterally. Word in Noise Test (WNT) [16] and the paired Dichotic Digit Test (DDT) [17] were conducted in a free recall approach $[16,18]$.

The reason to choose these two central tests is their high sensitivity and specificity to detect APD and the reason to choose a pair version of DDT is that the version of single DDT is very simple and the version of triple DDT, on the other hand, needs large memory demands [19]. Normative data of both tests were available for the target age groups and for each ear individually. If their scores were different from those of the normative data on the order of 2 SD or more, the result was interpreted as abnormal.

After meeting the inclusion criteria of the current study and based on the results of WNT and DDT as well as the results of counseling with the therapist, the case profile was observed to ensure lack of any co-exiting complications, but not limited to learning disorder, Attention Deficit Hyperactivity Disorder (ADHD), autism, etc.

The current study protocol was approved by the Ethics Committee of Tehran University of Medical Sciences with the IR.TUMS.FNM.REC.1397061 code. All parents participating in the study signed the written consent form. Statistical analysis was performed with SPSS version 22 . To analyze the findings, independent t-test was used to examine and compare the differences between normal and APD group, and to test the reliability of the test-retest, the paired samples t-test was used. ICC was examined for the in-depth stability of the whole scale. Finally, Cronbach's alpha was used to test the reliability of the collected data.

\section{Result}

The current study was conducted on 25 children with APD (12 males and 13 females, Mean \pm SD $=9.4 \pm 1.3$ years) and 25 normal children (14 males and 11 females; Mean $\pm \mathrm{SD}=9.5 \pm 1.4$ years $)$, and their parents completed the Fisher checklist. The mean, SD, minimum and maximum score of the Fisher checklists in the control and case groups are shown in Table 1 . The average score in the patient group was $49.6 \%(\mathrm{SD}=16.7 \%)$ and in the control group $94.7 \%(\mathrm{SD}=12.5 \%)$.

Statistical indices separately performed on the paired DDT for the right and left ears, as well as the different age groups, are summarized in Table 2. For each group, the mean and SD were reported. As observed in the Table 2 , in the different age ranges of the control group, the score was within the normal range. In the patient group, scores of more than two SDs were less than the average, which were considered abnormal. To eliminate the effect of age, independent samples t-test in each age group was performed separately and according to the average score of the test and the value of the t-statistic, there was a significant difference in the score of DDT between the patient and the control groups in all age groups $(\mathrm{P}<0.001)$

The results of the Right Ear Advantage (REA) in the control and patient groups are demonstrated in Table 3. The results of age adjustment in the independent t-test indicated a significant difference between the right and left scores in all age groups $(\mathrm{P}<0.001)$. There was also a significant difference in REA between the groups. This level in the control group was within the normal range and in the patient group was beyond the normal range.

The WIN scores for the right and left ear for different age groups are shown in Table 4. For each group, the mean and SD were reported. An independent samples

Table 1. Average, Mean and SD of the Fisher checklist scores in the studied groups

\begin{tabular}{cccccc}
\hline Population Studied & Average & SD & Mean & Minimum & Maximum \\
\hline Patient & 94.7 & 12.5 & 96 & 76 & 100 \\
Control & 49.6 & 16.7 & 52 & 20 & 72 \\
\hline
\end{tabular}


Table 2. Mean, SD, T and P Values of paired Dichotic Digit Tests for right and left ears and age in the studied groups

\begin{tabular}{|c|c|c|c|c|c|}
\hline Age & Ear & Population Studied & Mean \pm SD & $\mathbf{T}$ & $\mathbf{P}$ \\
\hline \multirow{2}{*}{8} & Right & $\begin{array}{l}\text { Patient } \\
\text { Control }\end{array}$ & $\begin{array}{c}50.62 \pm 2.39 \\
80.0 \pm 3.95\end{array}$ & 12.98 & $<0.001$ \\
\hline & Left & $\begin{array}{l}\text { Patient } \\
\text { Control }\end{array}$ & $\begin{array}{l}32.50 \pm 2.04 \\
68.0 \pm 3.25\end{array}$ & 18.9 & $<0.001$ \\
\hline \multirow{2}{*}{9} & Right & $\begin{array}{l}\text { Patient } \\
\text { Control }\end{array}$ & $\begin{array}{c}55.0 \pm 1.76 \\
85.50 \pm 2.09\end{array}$ & 24.9 & $<0.001$ \\
\hline & Left & $\begin{array}{l}\text { Patient } \\
\text { Control }\end{array}$ & $\begin{array}{l}40.50 \pm 2.09 \\
81.0 \pm 1.36\end{array}$ & 36.2 & $<0.001$ \\
\hline \multirow{2}{*}{10} & Right & $\begin{array}{l}\text { Patient } \\
\text { Control }\end{array}$ & $\begin{array}{l}62.08 \pm 1.88 \\
88.12 \pm 2.39\end{array}$ & 19.3 & $<0.001$ \\
\hline & Left & $\begin{array}{l}\text { Patient } \\
\text { Control }\end{array}$ & $\begin{array}{l}44.58 \pm 1.88 \\
83.85 \pm 3.22\end{array}$ & 24.52 & $<0.001$ \\
\hline \multirow{2}{*}{11} & Right & $\begin{array}{l}\text { Patient } \\
\text { Control }\end{array}$ & $\begin{array}{l}65.83 \pm 2.04 \\
90.41 \pm 1.88\end{array}$ & 21.7 & $<0.001$ \\
\hline & Left & $\begin{array}{l}\text { Patient } \\
\text { Control }\end{array}$ & $\begin{array}{l}50.41 \pm 1.88 \\
86.66 \pm 2.58\end{array}$ & 27.8 & $<0.001$ \\
\hline \multirow{2}{*}{12} & Right & $\begin{array}{l}\text { Patient } \\
\text { Control }\end{array}$ & $\begin{array}{l}68.75 \pm 10.44 \\
94.50 \pm 2.09\end{array}$ & 20.8 & $<0.001$ \\
\hline & Left & $\begin{array}{l}\text { Patient } \\
\text { Control }\end{array}$ & $\begin{array}{l}58.75 \pm 3.22 \\
91.50 \pm 2.85\end{array}$ & 16.2 & $<0.001$ \\
\hline
\end{tabular}

t-test revealed a significant difference between the mean scores of the WIN test in patient and control groups $(\mathrm{P}<0.001)$. To meet the face validity criteria, the face validity of each item should not be less than 1.5 [20]. The results of face validity of questions are given in Tables 5 and 6, separately. As demonstrated in the Tables 5 and 6 , all questions mostly had face validity more than 3 . Furthermore, the Cronbach's alpha for the checklist was 0.827 ; therefore, the checklist had intrinsic reliability.

The test-retest reliability was determined based on the degree of matching between the scores of the checklists in the two runs with a time interval of two weeks. Paired samples t-test was used to assess possible difference between the scores in the two sequential performances of the checklist. Table 7 shows the results of t-test for the two check-list runs with a two-week interval. The results indicated no significant differences between the scores of the checklist in two runs $(\mathrm{P}>0.05)$, and therefore, this checklist was highly reliable. According to the ICC value, 0.744 and 0.708 in the control and patient groups, respectively, there was a good correlation coefficient in the control and patient groups. According to the Cronbach's alpha coefficient, 0.85 and 0.71 in the patient and control groups, respectively, the internal reliability coefficient of the checklist was high.

\section{Discussion}

The current study aimed at investigating the translation and determining the validity and reliability of the Persian version of the Fisher checklist. The current study findings suggested that based on the results of DDT and 
Table 3. Mean, SD, T and P values of REA in the studied groups

\begin{tabular}{|c|c|c|c|c|}
\hline Age & Population Studied & Mean \pm SD & $\mathbf{T}$ & $\mathbf{P}$ \\
\hline \multirow{3}{*}{8} & Patient & $17.12 \pm 1.19$ & \multirow{3}{*}{3.25} & \multirow{3}{*}{$<0.01$} \\
\hline & & & & \\
\hline & Control & $12.0 \pm 1.22$ & & \\
\hline \multirow{3}{*}{9} & Patient & $14.50 \pm 0.93$ & \multirow{3}{*}{6.5} & \multirow{3}{*}{$<0.001$} \\
\hline & & & & \\
\hline & Control & $4.50 \pm 1.22$ & & \\
\hline \multirow{3}{*}{10} & Patient & $13.55 \pm 1.29$ & \multirow{3}{*}{7.1} & \multirow{3}{*}{$<0.001$} \\
\hline & & & & \\
\hline & Control & $4.37 \pm 1.19$ & & \\
\hline \multirow{3}{*}{11} & Patient & $11.41 \pm 1.35$ & \multirow{3}{*}{7.65} & \multirow{3}{*}{$<0.001$} \\
\hline & & & & \\
\hline & Control & $3.75 \pm 0.55$ & & \\
\hline \multirow{3}{*}{12} & Patient & $10.0 \pm 2.04$ & \multirow{3}{*}{3.75} & \multirow{3}{*}{$<0.01$} \\
\hline & & & & \\
\hline & Control & $3.0 \pm 0.5$ & & \\
\hline
\end{tabular}

Table 4. Mean, SD, T and P values of the Word in Noise Test in the studied groups

\begin{tabular}{|c|c|c|c|c|c|}
\hline Age & Ear & Population Studied & Mean \pm SD & $\mathbf{T}$ & $\mathbf{P}$ \\
\hline \multirow{2}{*}{8} & Right & $\begin{array}{l}\text { Patient } \\
\text { Control }\end{array}$ & $\begin{array}{c}15.20 \pm 1.24 \\
3.12 \pm 0.48\end{array}$ & 9.89 & $<0.001$ \\
\hline & Left & $\begin{array}{l}\text { Patient } \\
\text { Control }\end{array}$ & $\begin{array}{c}17.00 \pm 1.40 \\
3.76 \pm 0.29\end{array}$ & 10.38 & $<0.001$ \\
\hline \multirow{2}{*}{9} & Right & $\begin{array}{l}\text { Patient } \\
\text { Control }\end{array}$ & $\begin{array}{l}14.48 \pm 1.17 \\
2.80 \pm 0.43\end{array}$ & 9.3 & $<0.001$ \\
\hline & Left & $\begin{array}{l}\text { Patient } \\
\text { Control }\end{array}$ & $\begin{array}{c}16.24 \pm 1.14 \\
3.60 \pm 0.43\end{array}$ & 10.33 & $<0.001$ \\
\hline \multirow{2}{*}{10} & Right & $\begin{array}{l}\text { Patient } \\
\text { Control }\end{array}$ & $\begin{array}{c}13.60 \pm 0.73 \\
1.60 \pm 0.40\end{array}$ & 12.31 & $<0.001$ \\
\hline & Left & $\begin{array}{l}\text { Patient } \\
\text { Control }\end{array}$ & $\begin{array}{l}15.06 \pm 0.70 \\
2.80 \pm 0.32\end{array}$ & 13.35 & $<0.001$ \\
\hline \multirow{2}{*}{11} & Right & $\begin{array}{l}\text { Patient } \\
\text { Control }\end{array}$ & $\begin{array}{l}9.86 \pm 1.43 \\
1.06 \pm 0.43\end{array}$ & 5.86 & $<0.001$ \\
\hline & Left & $\begin{array}{l}\text { Patient } \\
\text { Control }\end{array}$ & $\begin{array}{c}11.06 \pm 1.41 \\
2.0 \pm 0.29\end{array}$ & 6.29 & $<0.001$ \\
\hline \multirow{2}{*}{12} & Right & $\begin{array}{l}\text { Patient } \\
\text { Control }\end{array}$ & $\begin{array}{l}7.80 \pm 1.40 \\
1.04 \pm 0.46\end{array}$ & 5.05 & $<0.01$ \\
\hline & Left & $\begin{array}{l}\text { Patient } \\
\text { Control }\end{array}$ & $\begin{array}{l}9.20 \pm 0.43 \\
1.20 \pm 0.43\end{array}$ & 6.23 & $<0.001$ \\
\hline
\end{tabular}


Table 5. Scores of face validity verifiers for experts on Persian version of the Fisher's Auditory Problems Checklist

\begin{tabular}{|c|c|c|c|c|}
\hline Item & $\begin{array}{c}\text { Points to the Quality of } \\
\text { Translation }\end{array}$ & $\begin{array}{c}\text { Points to the Cultural } \\
\text { Adaptation }\end{array}$ & $\begin{array}{l}\text { Score of the Appearance } \\
\text { of Translated Sentences }\end{array}$ & Face Validity \\
\hline 1 & 4 & 4 & 4 & 3.6 \\
\hline 2 & 4 & 4 & 4 & 3.2 \\
\hline 3 & 4 & 4 & 4 & 3.8 \\
\hline 4 & 3.71 & 3.85 & 3.85 & 4 \\
\hline 5 & 4 & 4 & 3.85 & 3.8 \\
\hline 6 & 3.85 & 3.85 & 3.85 & 3.5 \\
\hline 7 & 3.28 & 3.85 & 3.42 & 2.6 \\
\hline 8 & 4 & 4 & 3.71 & 3.6 \\
\hline 9 & 3.71 & 4 & 3.57 & 3 \\
\hline 10 & 4 & 4 & 3.85 & 3.8 \\
\hline 11 & 3.57 & 4 & 3.71 & 3.4 \\
\hline 12 & 4 & 4 & 3.85 & 3.4 \\
\hline 13 & 3.14 & 3.75 & 3.42 & 2.8 \\
\hline 14 & 4 & 4 & 3.85 & 3.2 \\
\hline 15 & 4 & 3.71 & 3.71 & 3.5 \\
\hline 16 & 3.85 & 3.85 & 3.85 & 3.6 \\
\hline 17 & 4 & 4 & 4 & 4 \\
\hline 18 & 3.85 & 4 & 3.85 & 3.6 \\
\hline 19 & 3.71 & 4 & 3.71 & 3.4 \\
\hline 20 & 3.85 & 4 & 4 & 3.8 \\
\hline 21 & 3.85 & 4 & 3.85 & 3.8 \\
\hline 22 & 3.85 & 4 & 3.71 & 3.6 \\
\hline 23 & 4 & 4 & 3.85 & 3.8 \\
\hline 24 & 4 & 4 & 4 & 4 \\
\hline 25 & 4 & 4 & 4 & 4 \\
\hline
\end{tabular}


Table 6. Scores of face validity indicators for parents on Persian version of the Fisher Auditory Problems Checklist

\begin{tabular}{|c|c|c|}
\hline Item & Understandable & Face Validity \\
\hline 1 & 3.65 & 3.1 \\
\hline 2 & 3.43 & 3 \\
\hline 3 & 3.88 & 3.6 \\
\hline 4 & 3.98 & 4 \\
\hline 5 & 3.6 & 3.4 \\
\hline 6 & 3.43 & 3.2 \\
\hline 7 & 3.1 & 2.6 \\
\hline 8 & 3.74 & 3.6 \\
\hline 9 & 3.57 & 3.2 \\
\hline 10 & 3.72 & 3.6 \\
\hline 11 & 3.5 & 3.4 \\
\hline 12 & 3.56 & 3.4 \\
\hline 13 & 3.1 & 2.8 \\
\hline 14 & 3.45 & 3.1 \\
\hline 15 & 3.62 & 3.5 \\
\hline 16 & 3.72 & 3.4 \\
\hline 17 & 3.82 & 3.8 \\
\hline 18 & 3.72 & 3.4 \\
\hline 19 & 3.47 & 3.4 \\
\hline 20 & 3.4 & 3.7 \\
\hline 21 & 3.7 & 3.6 \\
\hline 22 & 3.39 & 3.4 \\
\hline 23 & 3.52 & 3.4 \\
\hline 24 & 3.76 & 3.8 \\
\hline 25 & 3.9 & 3.6 \\
\hline
\end{tabular}

Table 7. Mean, SD, T and P values of word in noise test in the study groups

\begin{tabular}{|c|c|c|c|c|c|c|}
\hline $\begin{array}{l}\text { Population } \\
\text { Studied }\end{array}$ & $\begin{array}{l}\text { Fisher Test } \\
\text { Test-Retest }\end{array}$ & Mean \pm SD & $\begin{array}{l}\text { The Correlation } \\
\text { Coefficient Test-Retest }\end{array}$ & $\begin{array}{l}\text { Difference in Test- } \\
\text { Retest Mean Test }\end{array}$ & $\mathbf{T}$ & $\mathbf{P}$ \\
\hline \multirow{3}{*}{ Patient } & Test & $51.4 \pm 3.1$ & & & & \\
\hline & & & 0.791 & 9.78 & 2.1 & 0.052 \\
\hline & Retest & $55.44 \pm 2.97$ & & & & \\
\hline \multirow{3}{*}{ Control } & Test & $94.7 \pm 1.28$ & & & & \\
\hline & & & 0.782 & 3.98 & 0.4 & 0.692 \\
\hline & Retest & $95.1 \pm 1$ & & & & \\
\hline
\end{tabular}


WNT, the Persian version of the Fisher checklist had face validity and intrinsic reliability to detect APD.

In the current study, the Fisher checklist was first translated into Persian to evaluate its validity and reliability; this checklist was applied on 25 children aged 8 to 12 years with APD and 25 normal children in the same age group in two sequential stages with an interval of two weeks. Then, to check the effectiveness of the questionnaire to identify children with APD, the checklist was examined along with paired DDT and WIN tests.

The current study employed the paired DDT and WIN tests to determine the presence of APD in the patient group or the absence of APD in the control group, and the normative data of paired DDT and WIN tests in the studies by Rezapur et al. and Mahdavi et al. respectively $[16,17]$. Then the Fisher checklist was administered to the two groups (normal children in the control group and children with APD in the patient group).

The results of the Fisher checklist showed that the mean score in the control group was $94.7 \%(\mathrm{SD}=12.5 \%)$ (higher than $72 \%$, the cutoff point), and in the patient group 49.6\% $(\mathrm{SD}=16.7 \%)(<72 \%)$ [3]. This result was consistent with the results of Strange et al. They compared the results of the Fisher checklist with those of SSW (WT-22 speech in noise test). They revealed that children with APD in the Fisher checklist scored an average of $54 \%$ (range $32 \%$ to $72 \%$ ). In the current study, the Fisher checklist score in the patient group was $49.6 \%$ $(\mathrm{SD}=16.7 \%$ ) with the lowest score of $20 \%$ and the highest score of $72 \%$.

These results were in line with the results of Strange et al. and proved that the Persian version of the Fisher checklist also had a high degree of distinction between individuals with APD and normal people. Also, the results of formal validity and the results of Cronbach's alpha and ICC showed the high internal reliability and reliability of the checklist in the evaluation of APD. This checklist includes all the components of hearing processing; it can be done in the simplest language in the shortest possible time, and can well isolate normal children from the ones suspected to APD [3].

In order to assess the ability of children to listen in undesirable listening environments, questionnaires are usually used by specialists such as audiologists and speech therapists. However, questionnaires cannot definitely detect APD, but can provide a qualitative measure of the effect of this disorder on the child's auditory functions. APD questionnaires are designed to detect hearing problems. According to the research, children with lower scores in the test battery also have poor auditory performance in questionnaires [2].

Wilson et al. showed that the results of the questionnaire were correlated with the results and the scores of the frequency pattern tests and the DDT, which indicated the relationship between the subjective reports and the results of the auditory processing tests [21].

APD is not limited to children, and the number of adults with standard audiometry findings increase with hearing impairment [22]. APD may occur in children, adults, and the elderly. This disorder is commonly observed in people with normal peripheral hearing sensation, but can be accompanied by peripheral hearing loss [23]. The prevalence of APD in children is $2-3 \%$ and in adults is $23-70 \%$. Some of the sources outlined the prevalence in school-age children by $2-5 \%$. The prevalence in males was almost twice that of the females [3].

In spite of the prevalence of hearing processing problem in the past, the systematic therapeutic approach to the diagnosis and rehabilitation of APD in children began only about 30 years ago, and the focus of the research was to locate the disease lesion to identify the disorders caused in the affected population, and appropriate treatment [24]. If the APD is left untreated, it affects the child's life [4]. Appropriate treatment can result in better understanding in noise, more attention, and improved academic performance [22]. Therefore, timely diagnosis and early intervention are important.

Diagnosis of APD is difficult and not even detected in advanced brain imaging techniques (e.g. magnetic resonance imaging and computed tomography scan). There is no gold standard to identify APD. Detection of this disorder should be based on a robust test battery, including observation and accurate case history, accurate behavioral tests, and electrophysiological evaluations [23].

Due to the impossibility of fully evaluating complete diagnosis for all children or even adults, and the time and cost of doing so, and the difficulty of conducting behavioral assessments in children, the ASHA introduced the need for tools to screen APDs in 1991. The purpose of screening tools is to identify children at risk for APD requiring full evaluations. A central screening to identify people at risk for APD is used to identify those who need further evaluations [3]. In the end, it is suggested that this checklist, with a larger sample size, be performed on children with APD, and the results of this checklist be compared with the Buffalo Farsi test battery. 
According to the results of the current study, the Persian version of the Fisher Auditory Problems Checklist had good validity and reliability and can be recommended to screen people with APD along with other tools.

\section{Ethical Considerations}

\section{Compliance with ethical guidelines}

The current study protocol was approved by the Ethics Committee of Tehran University of Medical Sciences with the code: IR.TUMS.FNM.REC.1397061. All parents participating in the study signed the written consent form.

\section{Funding}

The present paper was extracted from the MSc. thesis of the first author, in Department of Audiology, School of Rehabilitation, Tehran University of Medical Sciences, Tehran, Iran.

\section{Authors' contributions}

Collecting and analysis the data and writing the original manuscript draft: Sanaz Shakiba; Designing and developing the protocol: Nematollah Rouhbakhsh, Sanaz Shakiba; Editing the manuscript: Nematollah Rouhbakhsh; Editing the manuscript: Ghasem Mohamadkhani; and Statistical analysis: Elham Faghihzadeh.

\section{Conflict of interest}

The authors declared no conflict of interest.

\section{Acknowledgments}

The authors acknowledge the financial support of Tehran University of Medical Sciences. More importantly, conducting this project is owed to Newsha and Ordibehesht Rehabilitation Centers for their helping in recruiting the participants.

\section{References}

[1] Emanuel DC, Ficca KN, Korczak P. Survey of the diagnosis and management of Auditory Processing Disorder. American Journal of Audiology. 2011; 20(1):48-60. [DOI:10.1044/10590889(2011/10-0019)]

[2] Tomlin D, Dillon H, Sharma M, Rance G. The impact of auditory processing and cognitive abilities in chil- dren. Ear and Hearing. 2015; 36(5):527-42. [DOI:10.1097/ AUD.0000000000000172] [PMID]

[3] Strange AK, Zalewski TR, Waibel-Duncan MK. Exploring the usefulness of Fisher's Auditory Problems Checklist as a screening tool in relationship to the buffalo model diagnostic Central Auditory Processing test battery. Journal of Educational Audiology. 2009; 15:44-52.

[4] Umat C, Mukari SZ, Ezan NF, Din NC. Changes in auditory memory performance following the use of frequency-modulated system in children with suspected Auditory Processing Disorders. Saudi Medical Journal. 2011; 32(8):818-24. [PMID]

[5] Sahli S. Auditory Processing Disorder in children: Definition, assessment and management. Journal of International Advanced Otology. 2009; 5(1):104-15. [DOI: 10.1080/16513860600568573]

[6] Katz J. The buffalo model questionnaire. Denver, Colorado: Educational Audiology Association; 2011.

[7] Smoski WJ, Brunt MA, Tannahill JC. Children's Auditory Performance Scale (CHAPS). Denver, Colorado: Educational Audiology Association; 1998.

[8] Anderson K, Smaldino J. Children's home inventory for listening difficulties. Oklahoma: Educational Audiology Review; 2000

[9] Anderson K, Smaldino J. Listening inventories for education: A classroom measurement tool. The Hearing Journal. 1999; 52(10):74-6. [DOI:10.1097/00025572-199910000-00009]

[10] Schow RL, Chermak G. Implications from factor analysis for Central Auditory Processing Disorders. American Journal of Audiology. 1999; 8(2):137-42. [DOI:10.1044/1059 0889(1999/012)]

[11] O'Hara B, Mealings K. Developing the Auditory Processing Domains Questionnaire (APDQ): A differential screening tool for Auditory Processing Disorder. International Journal of Audiology. 2018; 57(10):764-75. [DOI:10.1080/14992027.20 18.1487087]

[12] Anderson KL. Screening identification for targeting educational risk: In children identified by hearing screening or who have known hearing loss. Denver, Colorado: Educational Audiology Association; 1989 .

[13] Fisher L. Fisher's Auditory Problems Checklist. Bemidji, Minnesota: Life Products; 1976.

[14] Carmines EG,Zeller RA. Reliability and validity assessment. Thousand Oaks: Sage; 1979. [DOI:10.4135/9781412985642]

[15] Weir JP. Quantifying test-retest reliability using the Intraclass Correlation Coefficient and the SEM. The Journal of Strength \& Conditioning Research. 2005; 19(1):231-40. [DOI:10.1519/00124278-200502000-00038] [PMID]

[16] Mahdavi ME, Pourbakht A, Parand A, Jalaie S, Rezaeian $\mathrm{M}$, Moradiju E. Auditory recognition of words and digits in multitalker babble in learning-disabled children with dichotic listening deficit. Iranian Red Crescent Medical Journal. 2017 19(4):e42817. [DOI:10.5812/ircmj.42817]

[17] Shahmir B, Hajiabolhassan F, Mohammadkhani G, Tahaei AA, Jalaie S. Development and evaluation of the reliability of Persian version of double Dichotic Digit test in girls aged 7 to 
11 years. Auditory and Vestibular Research. 2015; 24(3):16470.

[18] Moradiju E, Mahdavi M, Zarrinkoob H, Tabatabaee S. [Relative and absolute test-retest reliability of several Persian auditory processing tests for dichotic listening and recognition of speech-in-noise in normal children aged 6-12 years (Persian)]. Journal of Rehabilitation Medicine. 2017; 6(4):1606. [DOI:10.22037/JRM.2017.110584.1389]

[19] Strouse A, Wilson RH. With Dichotic Digit recognition. Journal of the American Academy of Audiology. 1999; 10(4):219-29. [PMID]

[20] Zamanzadeh V, Ghahramanian A, Rassouli M, Abbaszadeh A, Alavi-Majd H, Nikanfar AR. Design and implementation content validity study: Development of an instrument for measuring patient-centered communication. Journal of Caring Sciences. 2015; 4(2):165-78. [DOI:10.15171/jcs.2015.017] [PMID] [PMCID]

[21] Wilson WJ, Jackson A, Pender A, Rose C, Wilson J, Heine $\mathrm{C}$, et al. The CHAPS, SIFTER, and TAPS-R as Predictors of (C) AP Skills and (C) APD. Journal of Speech, Language, and Hearing Research. 2011; 54(1):278-91. [DOI:10.1044/10924388(2010/09-0273)]

[22] Baran JA. Audiologic evaluation and management of adults with Auditory Processing Disorders. Seminars in Speech and Language. 1996; 17(3):233-44. [DOI: 10.1055/s2008-1064101] [PMID]

[23] Beck DL, Bellis TJ. (Central) Auditory Processing Disorders: Overview and amplification issues. The Hearing Journal. 2007; 60(5):44-6. [DOI:10.1097/01.HJ.0000285596.94334.55]

[24] Bamiou D, Musiek F, Luxon L. Aetiology and clinical presentations of Auditory Processing Disorders: A review. Archives of Disease in Childhood. 2001; 85(5):361-5. [DOI:10.1136/adc.85.5.361] [PMID] [PMCID] 


\section{Appendix}

Fisher's Auditory Problem Checklist

Student Name

Date

Grade
School

Observer
Position

Please place a check mark before each item that is considered to be a concern by the observer:

1. Has a history of hearing loss.

2. Has a history of ear infection(s)

3. Does not pay attention (listen) to instruction $50 \%$ or more of the time.

4. Does not listen carefully to directions-often necessary to repeat instructions.

5. Says "Huh?" and "What?" at least five or more times per day.

6. Cannot attend to auditory stimuli for more than a few seconds.

7. Has a short attention span. (If this item is checked, also check the most appropriate time frame

$$
\text { 0-2 minutes } \quad \text { 2-5 minutes } \quad \text { 5-15 minutes } \quad \text { 15-30 minutes }
$$

8. Daydreams - attention drifts - not with it at times.

9. Is easily distracted by background sound(s).

10. Has difficulty with phonics.

11. Experiences problems with sound discrimination.

12. Forgets what is said in a few minutes.

13. Does not remember simple routine things from day to day.

14. Displays problems recalling what was heard last week, month, year.

15. Has difficulty recalling sequence that has been heard.

16. Experiences difficulty following auditory directions.

17. Frequently misunderstands what is said.

18. Does not comprehend many words-verbal concepts for age/grade level.

19. Learns poorly through the auditory channel.

20. Has a language problem, (morphology, syntax, vocabulary, phonology).

21. Has an articulation (phonology) problem.

22. Cannot always relate what is heard to what is seen. 
23. Lacks motivation to learn.

24. Displays slow or delayed responses to verbal stimuli.

25. Demonstrates below average performance in one or more academic areas.

Scoring: Four percent credit for each numbered item not checked.

Number of items not checked .... $\times 4=\ldots$. 